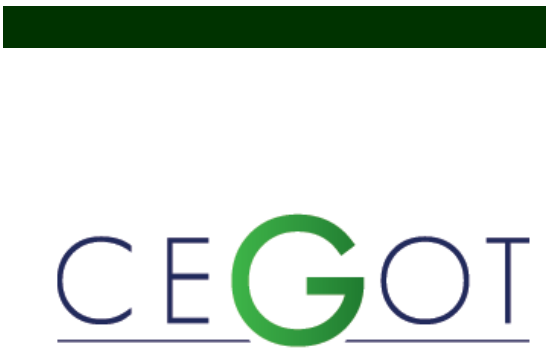

Centro de Estudos de Geografia e Ordenamento do Território
Geografia e Ordenamento do Território, Revista Eletrónica Centro de Estudos de Geografia e Ordenamento do Território http://cegot.org ISSN: 2182-1267

Silva, Paulo HenRique

Universidade Federal de Lavras

Departamento de Administração e Economia - UFLA

37200-000, Minas Gerais, Brasil

paulo-henrique-cds@hotmail.com

Dias Valadão, José de Arimatéia

Universidade Federal de Lavras

Departamento de Administração e Economia - UFLA

37200-000, Minas Gerais, Brasil

jose.valadao@ufla.br

Alves Prates, Lucas

Universidade Federal de Lavras

Departamento de Administração e Economia - UFLA

37200-000, Minas Gerais, Brasil

lucasalves2@yahoo.com.br

\title{
GESTÃO CULTURAL INTEGRADA DE TERRITÓRIO NA SERRA DO ESPINHAÇO: caminhos para
}

\author{
uma didática dos dilemas
}

INTEGRATED CULTURAL MANAGEMENT OF TERRITORY IN SERRA DO ESPINHAÇO: paths to a didactic of

dilemmas

Referência: Silva, Paulo Henrique; Dias Valadão, José de Arimatéia; Alves Prates, Lucas (2021). GESTÃO CULTURAL INTEGRADA DE TERRITÓRIO NA SERRA DO ESPINHAÇO: caminhos para uma didática dos dilemas. Revista de Geografia e Ordenamento do Território (GOT), № 21 (Junho). Centro de Estudos de Geografia e Ordenamento do Território, p. 03 - 33, dx.doi.org/10.17127/got/2021.21.001

\section{RESUMO}

O trabalho faz parte de um esforço conjunto de diagnósticos na microrregião de Presidente Kubistchek, na Serra do Espinhaço, por meio de uma parceria entre o Instituto Espinhaço e a Universidade Federal de Lavras (UFLA). Este trabalho busca analisar quais os limites e possibilidades para uma Gestão Cultural Integrada de Território (GCIT) na microrregião e propor alternativas metodológicas para novas intervenções no território. Como referência, foi usada a base conceitual de GCIT. Metodologicamente, foram analisados o diagnóstico da equipe UFLA que geraram dados por meio de Observação Participante e grupos focais. Os resultados mostram que o método usado para coleta de dados do pré-diagnóstico necessita de uma maior participação dos diversos grupos dos territórios, objetivando um empoderamento dos atores e uma visão transdisciplinar sobre os dados. Posteriormente, em um momento de diagnóstico, com todos os grupos debatendo os dados gerados, o estudo aponta as possibilidades de uma reflexão e compreensão do território em uma perspectiva de espaço, tempo e causalidade. Como forma de potencializar ações de médio e longo prazo, o estudo delineia a necessidade de Centros de Recursos e Espaços de 
Memórias que abram caminho para o debate entre gerações, visando uma apropriação simbólica dos territórios e de suas territorialidades, com o objetivo de estruturar propostas de médio e longo prazo para a microrregião de Presidente Kubistchek.

Palavras-chave: Gestão Cultural Integrada de Território, Formação, Patrimônio Cultural, Transdisciplinaridade.

\section{ABSTRACT}

The work is part of a joint diagnostic effort in the micro-region of Presidente Kubistchek, in Serra do Espinhaço, through a partnership between the Espinhaço Institute and the Federal University of Lavras (UFLA). This work seeks to analyze the limits and possibilities for an Integrated Cultural Territory Management (GCIT) in the micro-region and to propose methodological alternatives for new interventions in the territory. As a reference, the conceptual basis of GCIT was used. Methodologically, the diagnosis of the UFLA team was analyzed, which generated data through Participant Observation and focus groups. The results show that the method used to collect data from the pre-diagnosis requires greater participation by the various groups in the territories, aiming at empowering the actors and a transdisciplinary view on the data. Subsequently, at a time of diagnosis, with all groups debating the data generated, the study points out the possibilities for a reflection and understanding of the territory in a perspective of space, time and causality. As a way to enhance medium and long-term actions, the study outlines the need for Resource Centers and Spaces of Memories that open the way for debate between generations, aiming at a symbolic appropriation of territories and their territorialities, with the objective of structuring proposals medium and long term for the micro-region of Presidente Kubistchek.

Keywords: Integrated Cultural Management of Territory, Formation, Cultural heritage, Transdisciplinarity.

\section{Introdução}

A região da Serra do Espinhaço desde o período de 2005, quando foi reconhecida como Reserva da Biosfera, vem sendo objeto de vários estudos e experimentações com o intuito de demonstrar suas riquezas de fauna, flora e recursos hídricos, além de sua importância para o desenvolvimento regional. Por ser considerada um espaço geográfico com alto grau de biodiversidade, abarcando uma extensão de mais ou menos três milhões de hectares, abrangendo geopoliticamente 53 municípios em Minas Gerais e três grandes bacias hidrográficas brasileiras: Rio Doce, Jequitinhonha e Rio São Francisco, a região passou a ser entendida como um espaço de importante promoção de formas de desenvolvimento sustentável (Pereira; Gontijo \& Abreu, 2015). Por ser uma região de grandes recursos hídricos, a gestão das bacias hidrográficas sempre teve centralidade nas agendas das 
politicas públicas, pois na medida em que são espaços de interações biológicas (fauna e flora), físicas (solo, recursos hídricos), econômicos (atividades produtivas) e sociais (habitação, saúde, educação), passam a ser entendidas como espaços de grandes interações territoriais em diferentes níveis escalares (Haesbaert, 2004; Godecke \& Mauricio, 2015). Recentemente a região da Serra do Espinhaço foi palco de várias iniciativas voltadas para a equalização da relação homem e natureza e de visões globais e locais por meio do Projeto Plantando o Futuro Semeado Florestas Colhendo Águas na Serra do Espinhaço. Este projeto teve por objetivo plantar três milhões de mudas nativas de Mata Atlântica e Cerrado, e ao mesmo tempo, potencializar propostas de desenvolvimento sustentável (Instituto Espinhaço, 2017).

Por ser uma Reserva da Biosfera, a Serra do Espinhaço passou a ser reconhecida como um espaço de possibilidades para estudos e projetos prospectivos que alinhem desenvolvimento social, a proteção ambiental e novas oportunidades econômicas (Unesco, 2018). Neste sentido, no período de 2015 e 2016, o Instituo Espinhaço, entidade representativa da região, firmou um Termo de Colaboração com a CODEMIG visando executar o Projeto Plantando o Futuro na Serra do Espinhaço. E conjuntamente, essas entidades firmaram uma parceria com a Universidade Federal de Lavras, onde seria realizada uma iniciativa paralela ao Projeto Plantando Futuro no Espinhaço, com o objetivo de diagnosticar as potencialidades da região e propor futuras intervenções demonstrativas. Essa iniciativa específica foi nomeada de Gestão Cultural Integrada de Território na Serra do Espinhaço.

De maneira mais ampla, o Projeto Plantando o Futuro na Serra do Espinhaço, dividiu a macrorregião do Espinhaço, em Minas Gerais, em cinco núcleos que englobam cidades inter-relacionadas social, econômica e ambientalmente, totalizando cinquenta e três municípios. Nestes núcleos, foram elencadas cidades "polos" que concentrariam algumas atividades, como a implantação de um viveiro para produção das mudas de árvores do projeto. Esta divisão também teve como critérios a proximidade dos municípios e suas relações sociais, ambientais e econômicas (Plantando o Futuro, 2018).

Conjuntamente aos trabalhos de produção e plantio das mudas, o Instituto Espinhaço, a CODEMIG e a UFLA, organizaram então o processo de Gestão Cultural Integrada de Território (GCIT) no núcleo Gouveia (núcleo central), que é formado por 14 municípios, a 
princípio conectados ambientalmente, economicamente e socialmente, pois possuem um território integrado e banhado por importantes bacias hidrográficas e grande biodiversidade de fauna e flora (INSTITUTO ESPINHAÇO, 2018). E devido à crise hídrica que os municípios vinham enfrentando, o Instituto Espinhaço definiu que o início dos trabalhos se daria em Presidente KUBISTCHEK/MG pela microrregião do município ser a mais atingida pela escassez hídrica.

As atividades do projeto foram pautadas por meio de duas etapas na microrregião de Presidente Kubistchek onde foram delineados os objetivos do Programa Plantando Futuro na Serra do Espinhaço e como seria a participação da comunidade em todo o processo. E paralelo a isso, levantamentos de campo foram realizados sob coordenação de uma equipe da UFLA. Para subsidiar a atuação da equipe UFLA, foi delineada uma bibliografia de Gestão Cultural Integrada de Território, devido a esta literatura já estar sendo implementada em alguns municípios como Morro do Pilar/MG e Conceição do Mato Dentro, advindo de uma parceria do Instituto Espinhaço e o Instituto Tomar de Portugal, onde os atores envolvidos vinham colhendo efeitos concretos.

Os principais resultados dos trabalhos da equipe UFLA foram materializados em dois estudos científicos, um de cunho mais teórico e outro empírico. O primeiro estudo buscou delimitar a literatura base de todos os esforços relacionados a Gestão Cultural Integrada de Território, de forma a situá-la dentro de um marco teórico e de debates sobre Desenvolvimento Sustentável. O segundo estudo, por meio da referência de GCIT e Desenvolvimento Sustentável, foi proposto a partir das análises empíricas realizadas na microrregião de Presidente Kubistchek/MG. Os eixos centrais de GCIT usados no segundo trabalho: Matriz Territorial, Interlocução Institucional, Formação e Observatórios Territoriais, levaram às informações de como foi a construção histórica da região, as transformações físicas dos territórios, das inter-relações dos atores locais e como estes fatores levaram aos contextos atuais, com destaque para a escassez hídrica da região. E por meio deste espaço de diálogo e reflexão transdisciplinar, os atores puderam estruturar ideias sobre as possibilidades de curto, médio e longo prazo para a microrregião de Presidente Kubistchek/MG.

Desse modo, este estudo buscou analisar quais os limites e possibilidades para uma GCIT na microrregião de Presidente Kubistchek e propor alternativas metodológicas para novas 
intervenções de GCIT no microterritório estudado. A questão central que norteou foi como articular ações locais visando transformações regionais ou mesmo globais por meio dos eixos centrais propostos na literatura de GCIT na microrregião de Presidente Kubistchek/MG.

Para fazer essa discussão, o trabalho está estruturado em mais cinco seções além dessa introdução. A próxima seção apresenta os principais resultados do marco teórico do primeiro estudo e o contexto da realidade objeto do estudo. Na sequência é apresentada os principais resultados do estudo empírico e a forma do diagnóstico da situação-problema. As duas outras seções tratam da análise da situação-problema, sintetizando recomendações e algumas contribuições técnicas e metodológicas do trabalho. Por fim, é apresentada a conclusão.

\section{Contexto e realidade investigada}

\subsection{Agendas 2030 de desenvolvimento sustentável}

Em um contexto mais amplo, o trabalho parte da discussão sobre Desenvolvimento Sustentável e da complexidade e notoriedade que ela tem ganhado nos últimos anos, derivado dos debates que aconteceram desde o período de 1960 (Meadows, 1992; Sachs, 2007; Veiga, 2008). Neste sentido, a compreensão deste termo se configurou e reconfigurou durante uma trajetória de mais de meio século, por meio das interações entre os atores internacionais, nacionais e, mais recentemente, em nível local (Sachs, 2007; Veiga, 2008).

Como consequência, em 2012, na Conferência das Nações Unidas sobre Desenvolvimento Sustentável, Rio+20, os debates derivados das experiências pregressas reafirmaram algumas constatações importantes como: a erradicação da pobreza como elemento transversal já que continua sendo centro dos esforços das agendas internacionais; a necessidade de Políticas Públicas bottom-up, construídas a partir dos territórios, pois são estes espaços onde as pessoas constroem, historicamente e culturalmente, suas perspectivas, seus interesses, suas narrativas, por meio de um conjunto de relações e práticas; a necessidade de abordagens que contribuam, transdisciplinarmente, para novas compreensões dos territórios, onde os conhecimentos científicos e saberes locais sejam permeados entre 
global e local e; por meio destas constatações, os atores debaterem as possibilidades de médio e longo prazo para seus territórios (Oosterbeek, Werlen \& Caron, 2017). Esses debates são importantes para que a sociedade não caminhe para novas rupturas sociais, ambientais e econômicas, derivadas das consequências de pensamentos alienantes e de curto prazo (Oosterbeek, Werlen \& Caron, 2017).

Diante deste cenário, no ano de 2015, foi lançada a Agenda "Transformando Nosso Futuro Comum: A Agenda 2030 para o Desenvolvimento Sustentável”, derivada dos debates ocorridos no passado, e consequentemente, das experiências e novas compreensões adquiridas. Nela, os objetivos e metas a serem atingidas deveriam ser pensadas de forma integrada, indivisíveis e interconectadas (Oosterbeek, 2012; ONU, 2015). Neste sentido, a agenda colocou alguns elementos fundamentais, tais como: educação que leve em consideração a importância da diversidade cultural e de gênero, os saberes locais sendo subsidiados pelos científicos, e consequentemente, levando a produção de tecnologias apropriadas (ONU, 2015). Conjuntamente a estes elementos, a agenda traz a importância da participação de grupos vulneráveis na construção de políticas inclusivas proporcionando uma governança local (Ob.Cit.).

Neste contexto, depreende-se a necessidade uma nova percepção sobre os territórios, suas territorialidades e os níveis escaleres que estão operando nestes espaços, devido às constatações de 2012 e dos novos elementos colocados pela Agenda 2030 (Haesbaert, 2004; Oosterbeek, Werlen \& Caron, 2017). Diante deste cenário, a UNESCO, por meio do Conselho Internacional de Ciências (ICSU), do Conselho Internacional das Ciências Sociais (ISSC) e do Conselho Internacional de Filosofia e Ciências Humanas (CIPSH), instituiu o ano de 2016 como Ano Internacional para o Entendimento Global com o slogan de "construir pontes entre os pensamentos globais e ações locais", onde um amplo grupo de pesquisadores vinculados a instituições mundiais vem debatendo uma nova concepção de desenvolvimento global a partir de ações locais, por meio do que tem sido conhecido como Gestão Cultural Integrada do Território (GCIT) (Oosterbeek, Werlen \& Caron, 2017). 


\subsection{Construindo pontes entre a visão global e local por meio da GCIT}

Nesse sentido, a discussão de Gestão Cultural Integrada do Território (GCIT) vem ganhando relevância, principalmente por meio dos debates que aconteceram na Cúpula da Terra Rio + 20 e a necessidade de se construir pontes entre a visão global e as ações locais.

As principais constatações derivadas dos debates da Rio +20 residem em: as ações traçadas a nível internacional acabam criando lógicas injustas a nível local, pois estas ações chocam com as liberdades individuais dos indivíduos sem thes garantir meios de atuação. Uma segunda constatação reside no desenho das políticas públicas para promover equidade social e sustentabilidade ambiental, tendo suas bases de sustentação em visões equivocadas de crescimento econômico e distribuição de renda, o que acabou gerando novos problemas ambientais, principalmente a nível local. E uma terceira constatação que trata da problemática que por mais que se tenha avançado nas construções estratégicas dos planos de ações, as concepções teóricas usadas para materializar essas ações têm suas bases assentadas em entidades vazias de contradições (culturais, sociais ou econômicas) e, consequentemente, gerando conflitos e não vislumbrando possibilidades de médio e longo prazo (Oosterbeek, 2012; Oosterbeek, Werlen \& Caron, 2017).

Com base nestas constatações, a literatura de Gestão Cultural Integrada de Território parte de três compreensões: primeiro que entender a inter-relação, a interconexão e integração dos conceitos ambiental, social e econômico, perpassa por um elemento central que os une, a cultura (Oosterbeek, 2011). Segundo, que as intervenções a nível nacional e local não conseguiram projetar ações de médio e longo prazo, devido a se basearem em premissas interdisciplinares equivocadas e políticas públicas top-down. Como resultado, as políticas públicas se concentraram nos níveis estratégicos dos governos, sem compreender a diversidade cultural existentes nos territórios e suas implicações na efetivação das ações (Oosterbeek, Scheunemann \& Santos, 2013; Oosterbeek, Werlen \& Caron, 2017). Terceiro, as mudanças somente poderiam ser efetivadas a partir dos territórios, por meio de abordagens transdisciplinares que projetem o médio e longo prazo, conjuntamente a construção de políticas públicas a nível territorial (bottom-up) (Santos, 2000; Shiki \& Shiki, 2004; Dallabrida, 2016). 
Neste sentido, o território na literatura de GCIT passa a ter grande relevância para a compreensão da realidade, por ser a partir destes espaços que as pessoas se interrelacionam, criam vínculos, tem suas referências e narrativas construídas ao longo do tempo, e por meio desses fatores, definem os percursos a seguirem (Dallabrida, 2016; Oosterbeek, Werlen \& Caron, 2017). Consequentemente, estes percursos podem acarretar impactos diretos no meio natural e direta ou indiretamente no meio social, levando os vários grupos de um espaço geográfico a um dilema, definir novos percursos ou permanecer no mesmo formato em que se encontram. Porém, este momento de decisão pode ser precedido de contradições e conflitos difíceis de conciliar (Oosterbeek, 2018). Neste contexto, os territórios passam a ser entendidos como espaços tanto de relações de poder, como sociais, econômicas, ambientais e culturais (Raffestin \& Santana, 2013; Portugal \& Marques, 2007).

Estas relações que ocorrem nos territórios por meio dos sistemas locais de comunicação, intercâmbio, mediação e representação, contribuem para compreender como se estruturam as dinâmicas culturais destes espaços com o proposito de satisfação de demandas dos atores em diferentes escalas (Haesbaert, 2004; Oosterbeek, Cura \& Bastos, 2011; Oosterbeek, 2012; Oosterbeek, Scheunemann \& Santos, 2013; Oosterbeek, 2013).

A centralidade do elemento cultura, na perspectiva dos territórios, reside no fato de ser por meio deste elemento que se percebe as diversidades existentes nestes espaços, derivadas das interpretações, narrativas, percepções e sistemas de valores dos atores. Esta compreensão das relações por meio da cultura, segundo a literatura, contribui para entender os interesses dos indivíduos, as escolhas muita vezes contraditórias e mesmo conflituosas entre os grupos, dos quais podem resultar caminhos não consensuais, e desses impasses nos espaços geográficos, gerar debates sobre a permanência em um caminho ou seguir novos rumos, entendidos aqui como "dilemas" em que os grupos podem se encontrar nestas situações (Oosterbeek, 2013; Oosterbeek, 2012). Neste sentido, a literatura de GCIT coloca que um dos principais desafios da humanidade, principalmente a nível local, mais que resolução de problemas, é fazer uma Didática dos Dilemas (Oosterbeek, 2013; Oosterbeek, 2012; Oosterbeek, Scheunemann \& Santos, 2013).

Para compreender como os dilemas são percebidos nos diversos territórios, a literatura de GCIT discute quatro conceitos: "Matriz Territorial, Interlocução Institucional, Formação e 
Observatórios Territoriais", que objetivam identificar o dilema e debater as perspectivas que giram ao entorno desse elemento. A discussão destes quatro conceitos tem o intuito de contribuir para compreensão dos territórios, a diversidade cultural identitária e consequentemente do dilema ou dilemas existentes a nível local e quais as possibilidades de médio e longo prazo para uma didática destes dilemas.

Para compreender a diversidade de olhares, percepções, interesses e sistemas de valores dos diferentes atores dentro do mesmo território e, consequentemente dos dilemas que possam existir, o conceito de Matriz Territorial passa a ter relevância. Este conceito parte do entendimento que as pessoas nos territórios necessitam atender demandas primárias como acesso a água, alimentação, moradia, ao mesmo tempo em que as mais variadas relações econômicas surgem para atender demandas em diferentes escalas e necessidades e acabam por intervir nestes espaços físicos (Santos, 2000; Shiki \& Shiki, 2004; Werlen \& Caron, 2017). Estas intervenções ocorrem por meio de conhecimentos e técnicas transmitidas por meio da comunicação entre as gerações, derivadas de um conjunto de relações, espaços de referência, conjunto de práticas, sinônimo de pertencimento, relações de poder, relações sociais, econômicas e, consequentemente ambientais, entendidas aqui como territorialidades (Santos, 2000; Haesbaert, 2004; Dallabrida, 2016). O que conecta a um segundo conceito, que são as formas de Interlocução Institucional, ou seja, como estas pessoas se articulam nos espaços de comunicação, mediação e representação (Oosterbeek, Scheunemann \& Santos, 2013; Werlen \& Caron, 2017).

A comunicação nestes espaços institucionais ganha relevância, pois é por meio do diálogo que as pessoas se posicionam no mundo e definem os percursos a serem seguidos nos territórios (Dallabrida, 2016). Mas como bem pondera Saquet (2011), estes espaços quando existem não são apropriados de forma democrática, o que suscita conflitos, porém, segundo Dallabrida (2015), diante das contradições que permeiam os conflitos, são estes espaços que os atores buscam construir e validar posições para harmonizar percursos a serem seguidos. Para Haesbaert (2004), é neste ponto que ocorre uma diversidade de posicionamentos, derivados da diversidade cultural existentes em cada espaço geográfico, pois são estes espaços que comportam múltiplos atores, cada um em seus territórios e com suas territorialidades que podem gerar contradições muitas das vezes conflituosas. Estes conflitos existentes nos espaços geográficos advindos dos diferentes grupos que o 
compõem, têm como uma de suas variáveis a pluralidade de lentes derivadas de saberes locais e científicos, e como estes saberes se relacionam na realidade. Neste sentido, a transdisciplinaridade passa a ser base para compreender os territórios. Transdisciplinaridade esta entendida como saber do mundo, onde tanto ciência como saberes locais estão contribuindo para um novo entendimento da realidade (permeando uns aos outros) e o resultado não é um conhecimento científico, mas derivado de um diálogo (político), gerando uma compreensão mais complexa dos territórios (Santos, 2000; Hissa, 2011).

A discussão de transdisciplinaridade conecta-se ao conceito de formação, pois a literatura de GCIT parte da constatação que os conhecimentos científicos e saberes locais devem ser permeados uns aos outros para a construção de novos conceitos transdisciplinares (Oosterbeek, Cura \& Bastos, 2011; Oosterbeek, Werlen \& Caron, 2017). Neste sentido, a formação tem papel importante neste debate, pois uma formação transdisciplinar contribui para uma nova visão local, plasmada em novos conceitos e dando domínio técnico aos atores para negociações sociotécnicas (Shiki \& Shiki, 2004; Osterbeek, Werlen \& Caron, 2017). Para tanto, segundo a literatura de GCIT, a tecnologia nesse cenário passa a ter papel fundamental, pois é por meio de cidadãos conscientes e preparados, reflexivamente, que se torna possível construir cenários de governança de médio e longo prazo (Oosterbeek, 2013; Oosterbeek, Werlen \& Caron, 2017).

Mas como proporcionar esses espaços de reflexão e unir perspectivas diferentes e muitas vezes conflitantes em torno de projetos futuros? É por meio desta questão complexa que a literatura de GCIT traz o debate em torno dos Centros de Recursos, que seriam espaços de formação dos diversos atores de um território, oferecendo desde especializações acadêmicas a formações transversais do conhecimento para os mais variados grupos. Ao mesmo tempo em que os Espaços de Memórias subsidiariam a formação nestes centros de recursos, oferecendo um acervo histórico dos espaços geográficos e proporcionando a construção do saber, por meio de interações entre atores e ambientes para reflexão e sociabilidade (Oosterbeek, 2012; Oosterbeek, 2013). Estes dois locais, Centros de Recursos e os Espaços de Memórias, passam a ser entendidos como lugares de reflexão transdisciplinares e prospectivos (construção de ações), tendo como diretriz central a formação do capital humano em uma perspectiva cultural identitária (Santos, 2008; 
Scheunemann \& Oosterbeek, 2012). Neste cenário, o Patrimônio Cultural tem papel fundamental para suavizar as barreiras de visões de mundo, dos vários grupos existentes nos territórios, pois o patrimônio de um território representa as apropriações simbólicas no espaço e no tempo de uma sociedade e lhes confere convergências e bases sobre interesses comuns (Oosterbeek \& Scheunemann, 2012). Nesta perspectiva, a reflexão sobre os territórios parte de uma visão cultural identitária, objetivando valorizar o Patrimônio Cultural por meio da compreensão do espaço (territórios), tempo (dinâmicas) e causalidade (ocorrência das dinâmicas nos territórios), partindo de um debate entre gerações. Este debate passa a ter relevância pelo fato da troca de saberes territoriais contribuir para problematização das questões em profundidade e complexidade, e para a construção de novas possibilidades logísticas de médio e longo prazo (Scheunemann \& Oosterbeek, 2012).

Como subsídio à construção destes cenários, um quarto conceito passa a ter conexão com os demais, que são os Observatórios Territoriais. Estas tecnologias e ferramentas tecnológicas tem grande importância para a formação de bases de dados sobre os territórios. E estas bases de dados são subsídios para construção de informações reflexivas sobre os territórios. Porém, de acordo com a literatura de GCIT, estes dados devem ser permeados pelos conhecimentos territoriais, principalmente os saberes locais, como forma de valorar as informações a serem produzidas (Oosterbeek, Scheunemann \& Santos, 2013; Oosterbeek, Werlen \& Caron, 2017).

A Figura 1 reflete a discussão sobre GCIT, sem a finalidade de delimitar um conceito geral, mas de mostrar a importância da transdisciplinaridade, objetivando discutir os territórios em toda a sua complexidade cultural, social, econômica e ambiental.

A Figura 1 mostra as novas compreensões que a literatura de GCIT, tendo por base as experiências pregressas de debates sobre desenvolvimento sustentável a nível internacional, nacional e local. Conjuntamente a estas experiências, a literatura traz a importância dos territórios, da diversidade cultural, e como consequência, dos percursos escolhidos pela sociedade (Oosterbeek; Werlen \& Caron, 2017). Neste sentido, a literatura de GCIT deriva dessas novas compreensões e que vem sendo construída a partir dos conceitos Matriz Territorial, Interlocução Institucional, Formação e Observatórios Territoriais, que coloca em debate as complexidades existentes nos territórios (Oosterbeek, Werlen \& Caron, 2017). 


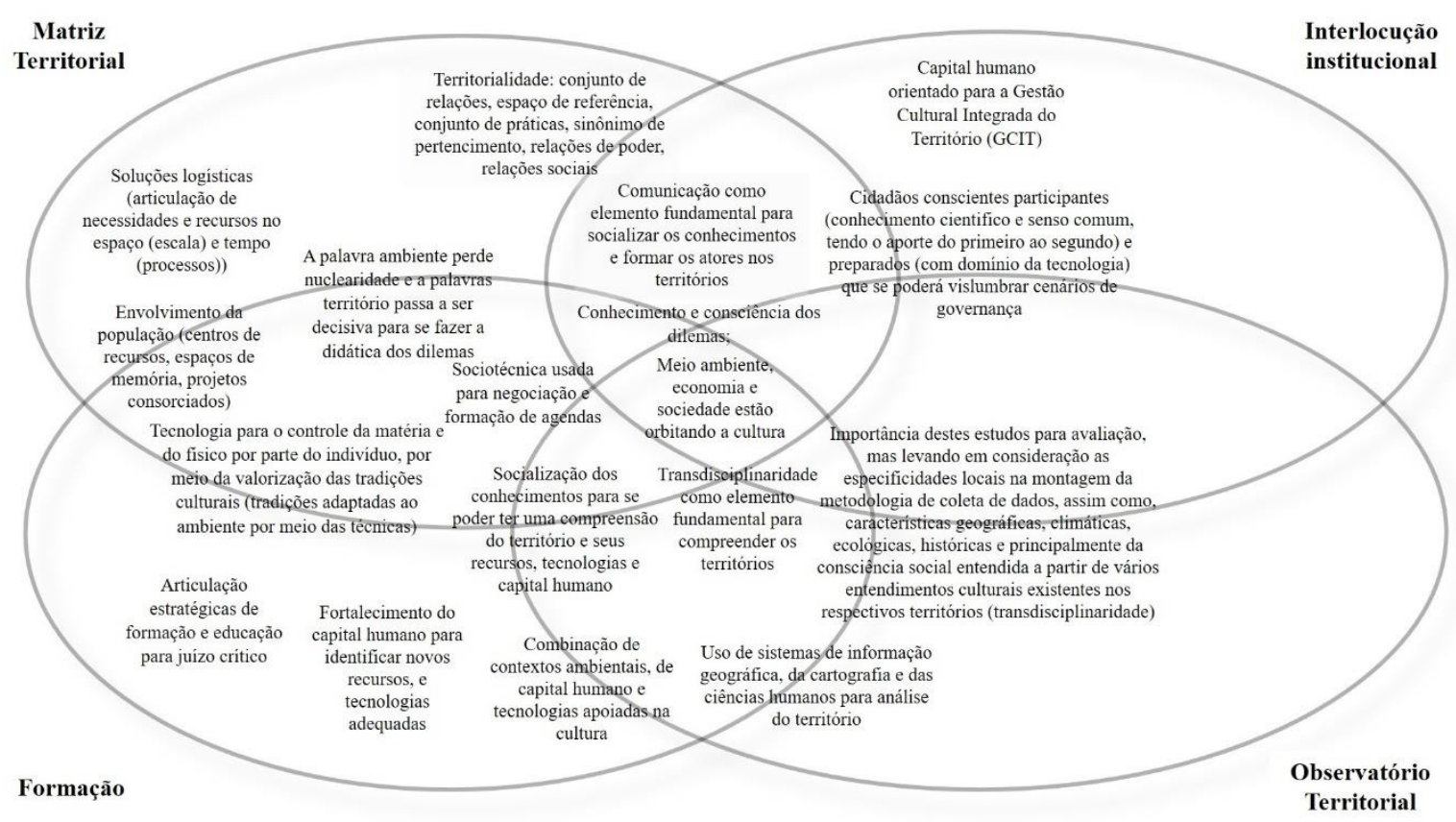

Figura 1 - Gestão Cultural Integrada de Território

Fonte: Elaborado pelos autores

\subsection{Projeto "Plantando o Futuro na Serra do Espinhaço"}

Diante destas compreensões globais e locais que se insere a região da Serra do Espinhaço. A região da Serra do Espinhaço em Minas Gerais tem uma extensão de mais ou menos três milhões de hectares, abrangendo 53 municípios (Pereira, Gontijo \& Abreu, 2015). Devido à extensão territorial, a região concentra uma importante área de divisão de águas, abarcando o Rio Doce, Jequitinhonha e Rio São Francisco, além de possuir uma diversidade de fauna e flora relevantes para a biodiversidade do país (Pereira, Gontijo\& Abreu, 2015).

Com o objetivo de preservar as riquezas naturais e paisagísticas da região, em 2005, a Serra do Espinhaço foi reconhecida como um Patrimônio da Biosfera. As regiões da biosfera, de acordo com o Programa Homem e Biosfera (MaB-Man and the Biosphere), são regiões com grande biodiversidade e são importantes para construir cenários que integrem meio ambiente e sociedade (Unesco, 2018). Neste sentido, estes espaços geográficos tem grande relevância para realização de estudos e iniciativas que alinhem valorização dos patrimônios naturais e culturais a formas de desenvolvimento sustentável (Unesco, 2018).

É nesse sentido mais global que a gestão cultural integrada de território foi proposta na Serra do Espinhaço, em Minas Gerais. Desde o período de 2013-14, a discussão sobre GCIT 
vem sendo realizada na Serra do Espinhaço, com efeitos concretos em Morro do Pilar e Conceição do Mato Dentro. Neste período, um quadro de atores a nível internacional, nacional, regional e local (figura 2) foram mobilizados sob a articulação e centralidade do Instituto Espinhaço, onde protocolos de intenções foram assinados com objetivo de criar uma agenda que produzisse uma ponte entre compreensões globais e ações locais.

\begin{tabular}{|c|c|c|c|}
\hline Internacional & Nacional & Regional & Local \\
\hline $\begin{array}{l}\text { Conselho Internacional de } \\
\text { Filosofia e Ciências Humanas }\end{array}$ & $\begin{array}{l}\text { Universidade federal de Santa } \\
\text { Maria (UFSM) }\end{array}$ & $\begin{array}{l}\text { Fundo de Amparo a Pesquisa de } \\
\text { Minas Gerais (FAPEMIG) }\end{array}$ & Município de Morro do Pilar \\
\hline Herity Internacional (Itália) & $\begin{array}{l}\text { Universidade federal de Lavras } \\
\text { (UFLA) }\end{array}$ & Empresa Manabi S.A & $\begin{array}{l}\text { Município de Conceição do Mato } \\
\text { Dentro }\end{array}$ \\
\hline Município de Mação (Portugal) & $\begin{array}{l}\text { Universidade federal de Brasília } \\
\text { (UNB) }\end{array}$ & $\begin{array}{l}\text { Ordem dos Advogados do Brasil - } \\
\text { Seccional de Minas Gerais }\end{array}$ & $\begin{array}{l}\text { Instituto Espinhaço (Conceição do } \\
\text { Mato Dentro) }\end{array}$ \\
\hline $\begin{array}{l}\text { Comunidade Internacional do } \\
\text { Médio Tejo (Portugal) }\end{array}$ & $\begin{array}{l}\text { Universidade do Extremo Sul de } \\
\text { Santa Catarina (UNESC) }\end{array}$ & & \\
\hline Universidade de Jena (Alemanha) & & & \\
\hline $\begin{array}{l}\text { Instituto Politécnico de Tomar } \\
\text { (Portugal) }\end{array}$ & & & \\
\hline Apheleia (União Europeia) & & & \\
\hline Universidade de Macau (China) & & & \\
\hline $\begin{array}{l}\text { Associação de Desenvolvimento } \\
\text { Pinhal Maior (Portugal) }\end{array}$ & & & \\
\hline
\end{tabular}

Figura 2 - Atores mobilizados nos primeiros trabalhos de GCIT

Fonte: Elaborado pelos autores

No período de 2014-15, as articulações desses atores começaram a perder força e centralidade, principalmente por parte dos atores exógenos (internacionais), devido aos problemas de financiamento das ações feito pela empresa mineradora da região de Morro do Pilar, porém, todo o aprendizado e repertório construído acabou sendo apropriado pelo Instituto Espinhaço que passou a coordenar os esforços na região.

Para tanto, no ano de 2016, o Instituto Espinhaço, ONG representativa da região da Serra do Espinhaço, por meio de um Termo de Colaboração com a CODEMIG, iniciaram o Projeto 
Plantando o Futuro Semeado Florestas Colhendo Águas na Serra do Espinhaço (Instituto Espinhaço, 2018). O objetivo do projeto é plantar três milhões de mudas características de Mata Atlântica e Cerrado, por meio da implantação de viveiros em cinco regiões (núcleos) da Serra. Em cada núcleo foram definidas cidades "polos" que concentrariam a implantação de um viveiro para produzir as mudas de árvores do projeto. Sendo que, no ano de 2016, a cidade de Gouveia/Minas Gerais que representa o núcleo da região central, foi definida como o primeiro núcleo a receber as atividades, devido aos problemas de escassez hídrica que este núcleo vinha enfrentando nos últimos anos. A região de Gouveia engloba 14 municípios com conexões ambientais, econômicas e sociais e possuem um território integrado e banhado por importantes bacias hidrográficas (Rio Doce, Rio Jequitinhonha e Rio São Francisco), como consta na figura 3, e grande biodiversidade de fauna e flora (Plantando Futuro, 2018).

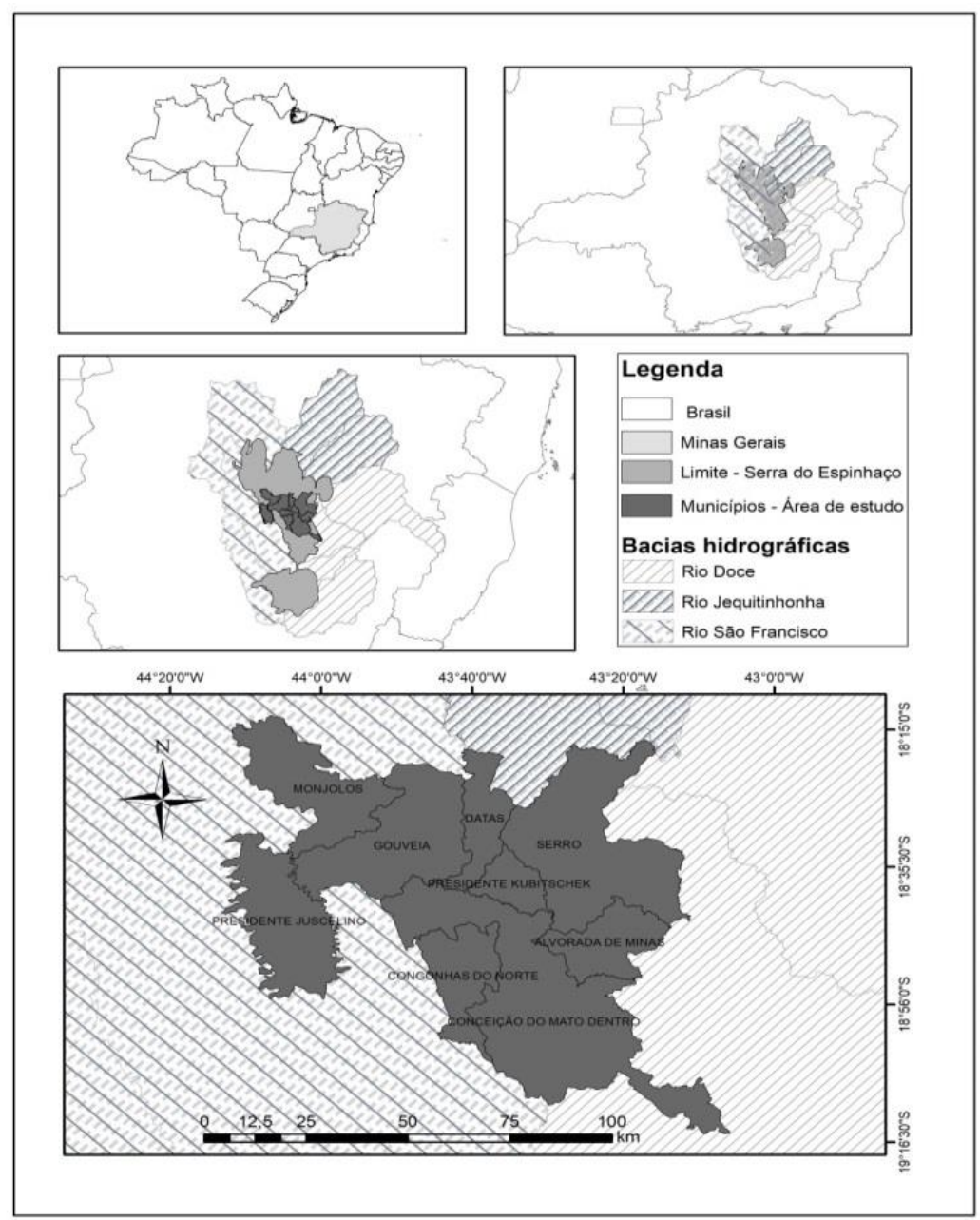

Figura 3 - Municípios do Núcleo Gouveia Fonte: Elaborado pelos autores 
Dos quatorze municípios do núcleo, o Instituto Espinhaço mobilizou nove municípios que se comprometeram a participar enviando representantes de suas cidades ao município de Presidente Kubistchek, cidade que concentraria a apresentação do projeto e demais iniciativas. Os principais atores, além dos institucionais (representantes do executivo, legislativo e judiciário), foram representantes de Sindicatos dos Trabalhadores Rurais, Cooperativa de Trabalhadores Rurais, Comunidades Tradicionais, Associação de Trabalhadores Rurais, Associação Comercial, Sindicato Comercial, Associação Industrial, Emater, Epamig, Instituto Estadual de Floresta de Minas Gerais, Instituições de Educação Básica, Instituições de Ensino Superior, Ministério Público, Agencias Governamentais, ONG's e OSCIP's.

Dentro deste quadro geral, o Instituto Espinhaço, na tentativa de potencializar as ações do projeto, atender aos propósitos das Reservas da Biosfera e avançar na implantação dos Objetivos do Desenvolvimento Sustentável, realizou uma parceria com a Universidade Federal de Lavras para a realização de um amplo diagnóstico. O propósito deste diagnóstico foi levantar a situação dos municípios e potencialidades da microrregião, além de construir uma Agenda, paralelamente ao Projeto Plantando o Futuro, visando potencializar as ações para além do plantio e construir projetos demonstrativos. Esse trabalho foi rotulado de GCIT, e passou a ser executado a partir de 2016.

\section{Metodologia}

O presente trabalho parte, assim, da oportunidade gerada na realização desse projeto de Gestão Cultural Integrada de Território na Serra do Espinhaço para refletir sobre os limites e possibilidades existentes na microrregião de Presidente Kubistchek pela ótica da GCIT. Para isso, foi realizada uma pesquisa documental, tendo por base o método de diagnóstico usado pela equipe UFLA, conforme descrito na introdução, e os resultados do estudo empírico produzido pelos autores, nos quais foi gerada uma densa descrição da microrregião de Presidente Kubistchek/MG. Esse trabalho contribuiu para sintetizar a compreensão dos fenômenos que vem ocorrendo na região, de acordo com o estudo empírico, e correlacionalos com as categorias de análise de GCIT do estudo teórico da literatura (GIL, 2002). Assim, o seu processo metodológico ocorreu em três fases. 
1a fase: foi lançado mão do método de construção do diagnóstico da equipe UFLA, e os principais resultados do segundo trabalho, conforme mencionado na introdução, que contribuíram para compreender a crise hídrica em debate na região e as possíveis alternativas e suas limitações (seção 4). Esta fase ocorreu em três etapas:

1a etapa: nesta etapa foram sintetizados os principais resultados das observações participantes sobre os processos históricos de desenvolvimento da microrregião de Presidente Kubistchek/MG, com o intuito de identificar os fatores que contribuíram para a ocorrência da crise hídrica (subseção 4.1) (Gil, 2002).

2a etapa: nesta etapa foram sintetizados os resultados das observações participantes dos grupos focais, que debateram as possibilidades de uma GCIT na microrregião de Presidente Kubitschek/MG, derivadas do fenômeno crise hídrica, e que foram inseridas na matriz "Novas compreensões locais sobre a Gestão Hídrica" e validadas por uma plenária geral (subseção 4.2) (Mónico et al, 2017).

3a etapa: nesta etapa foram delimitados os principais encaminhamentos na construção da de uma "Agenda comum de Desenvolvimento" da microrregião e os limites para materializa-la (subseção 4.3).

2a fase: nesta fase foi estruturada uma seção (Contribuições técnicas e Metodológicas) para ponderar os principais limites e possibilidades para futuras intervenções metodológicas tendo por base a literatura de GCIT e algumas proposições a serem trabalhadas na região para a construção de uma Gestão Cultural Integrada de Território na microrregião de Presidente Kubistchek.

3a fase: na terceira fase estruturamos uma seção de conclusão, onde sintetizamos as principais compressões do trabalho, buscamos responder o objetivo deste estudo e fizemos proposições de futuras pesquisas. 


\section{Diagnóstico da microrregião de presidente Kubistchek/MG e suas potencialidades de médio e longo prazo}

\subsection{0 diagnóstico da microrregião de Presidente Kubistchek}

O trabalho realizado por pesquisadores da UFLA partiu, inicialmente, de um pré-diagnóstico com a contribuição do Instituto Espinhaço, onde foram levantados dados cartográficos, principalmente das bacias hídricas da região além de aspectos físicos do território. Uma segunda fonte de dados de grande relevância foram os atores, os principais grupos de interesses e pessoas foram prefeitos, secretários municipais, vereadores, representantes de sindicatos de produtores rurais, trabalhadores rurais, comunidades tradicionais, quilombolas, representantes de associações comunitárias, ONGs, CODEMIG, IEF, EMATER e universidades. Estes atores seriam convidados a participar de rodada de debates e contribuir, por meio de suas perspectivas, para a compreensão da formação da região. Estas representações estão localizadas nas cidades de Gouveia, Conceição do Mato Dentro, Monjolos, Datas, Presidente Kubitschek, Presidente Juscelino, Serro e Congonhas do Norte e Alvorada de Minas. Partindo destas informações, foram estruturados roteiros tendo por base a literatura de Gestão Cultural Integrada de Território de forma a subsidiar uma contextualização da intervenção a ser proposta.

Posteriormente ao levantamento do pré-diagnóstico, foi construído um evento, denominado Plantando o Futuro com Gestão Integrada de Território: Propostas para o Entendimento Global a partir de Ações Locais visando os ODS, com o propósito de compreender a microrregião de Presidente Kubitschek, por meio das perspectivas dos atores locais. Com a identificação dos atores no pré-diagnostico, o evento foi construído de forma a subsidiar uma diversidade de percepções sobre a realidade. Para tanto, após uma apresentação do projeto Plantando Futuro na Serra do Espinhaço, foram formados grupos focais, dividindo os atores de forma heterogênea para compreender a formação da região e os dilemas que possivelmente poderiam existir no microterritório. Conjuntamente ao diagnóstico, o grupo de pesquisadores, fazendo uso do método observação participante, fizeram uma coleta de dados gerando alguns resultados. A Figura 4 foi gerada, por meio do método Observação Participante, considerando as compreensões locais para entender os conhecimentos e logísticas dos territórios. 


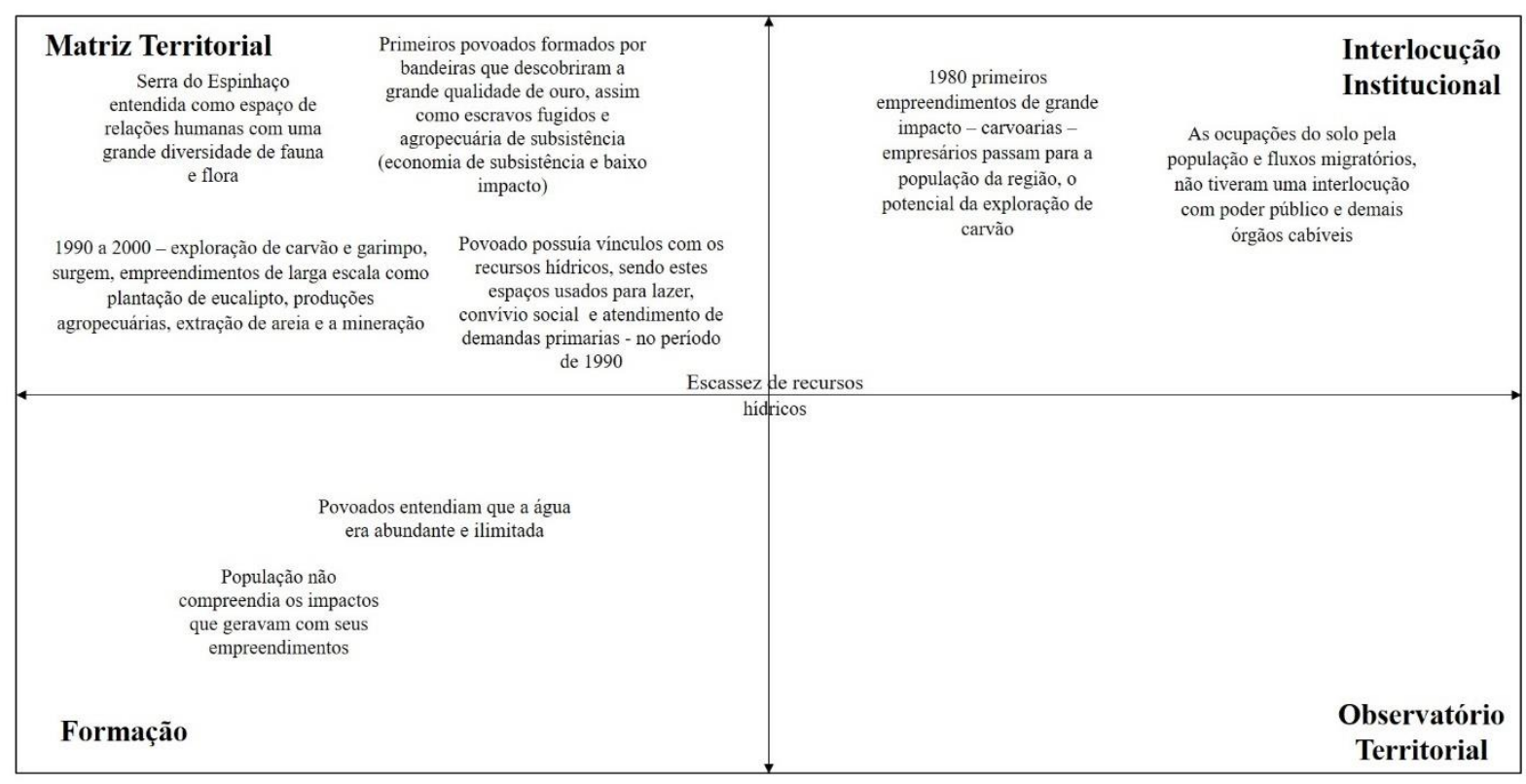

Figura 4 - Fluxo de espaço, tempo e causalidade dos primeiros povoados até 2000 Fonte: Elaborado pelos autores

Por meio da observação (figuras 4 e 5), os atores apontaram como elemento central do debate a Escassez de Água na região e que os dilemas existentes nos territórios partem dessa problemática. Por meio das percepções dos atores, foram colocados que a formação dos primeiros povoados da região começou com escravos fugidos de fazendas da região e por alguns agricultores. Estes grupos vieram para a região devido à disponibilidade de ouro, mas acabaram por exercer outras atividades como a produção de alimentos de subsistência e culturas artesanais. Neste sentido, depreende-se que os conhecimentos e logísticas de subsistência não impactavam a água da região nesta época (Scheunemann \& Oosterbeek, 2012). 

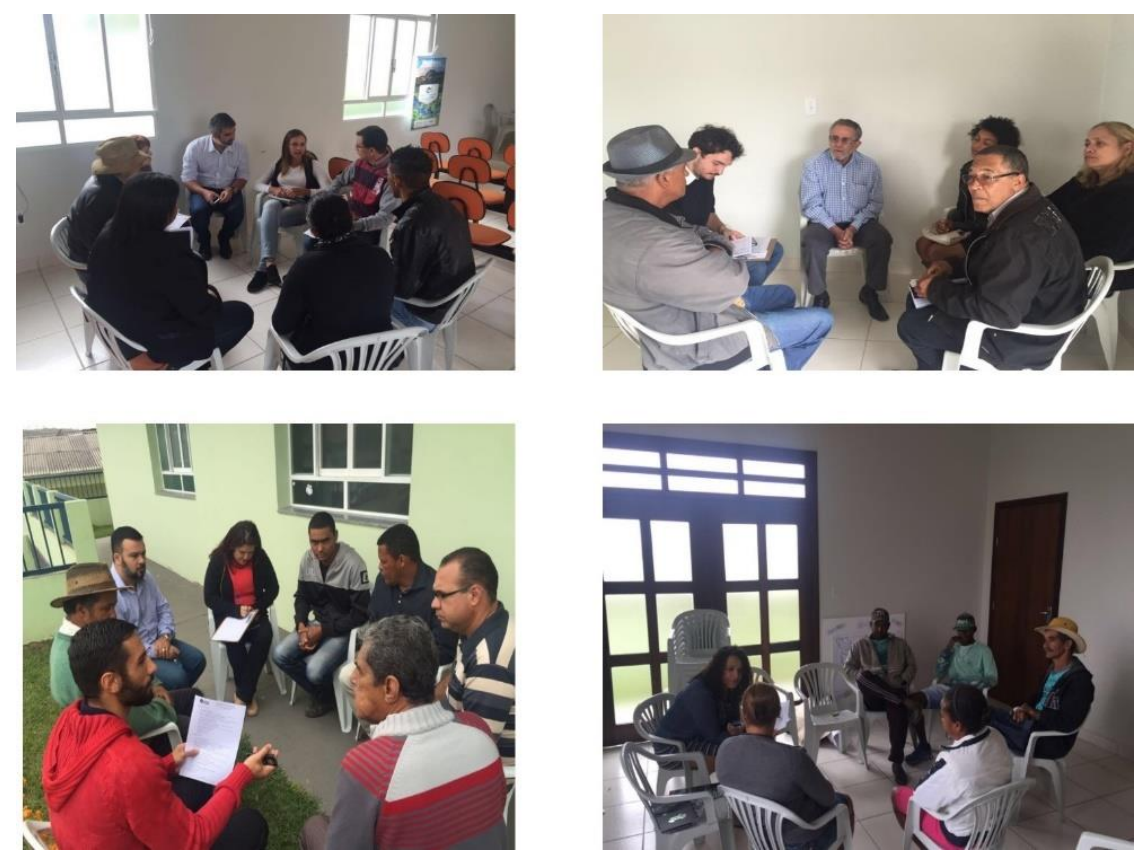

Figura 5 - Imagens das observações participantes realizadas sobre os grupos focais Fonte: Elaborado pelos autores

Posteriormente, a partir do período da década 1980, devido ao crescimento da siderurgia nacional, e pelo fato das populações crescerem, diversificarem e demandarem mais acesso a recursos primários, algumas intervenções em larga escala começaram a ser desenvolvidas. Neste sentido, as atividades de garimpo e de produção de carvão acabaram por intensificar o desmatamento e consequentemente impactaram as águas da região. Neste ponto, alguns conflitos aparecem devido a uma assimetria de informações entre empresários e povoado local, no sentido de produção em larga escala como forma de retorno econômico, sem considerar as possíveis causas negativas sobre o meio ambiente.

No período da década de 1990 a 2000, a economia se diversificou devido ao crescimento da população, e consequentemente das demandas locais. Neste sentido, a produção de carvão intensificou conjuntamente a diversificação da economia, com o surgimento da monocultura de eucalipto, que segundo os atores locais, eram manejados irregularmente próximos aos cursos d'água, inserção da agropecuária em larga escala e formação de pastagens, além de outras formas de extração mineral que impactaram diretamente a água e o solo da região. Esta diversificação da econômica e consequentemente da produção, segundo os atores locais, levaram a um fluxo migratório para a região, gerando ocupações do solo que impactaram os espaços naturais. 
Partindo destas constatações, os atores puderam refletir sobre os principais impactos gerados sobre a região, derivada das escolhas feitas no passado e o dilema que se impõe a eles, "continuar com o percurso escolhido no passado e consequente a escassez hídrica", ou trilhar novos caminhos e amenizar estes impactos sobre os espaços naturais. Partindo da compreensão construída entre os atores sobre a microrregião, eles colocaram algumas iniciativas isoladas que vem sendo realizadas nos territórios e que poderiam ser pontos de partida para as mudanças almejadas (Figura 6).

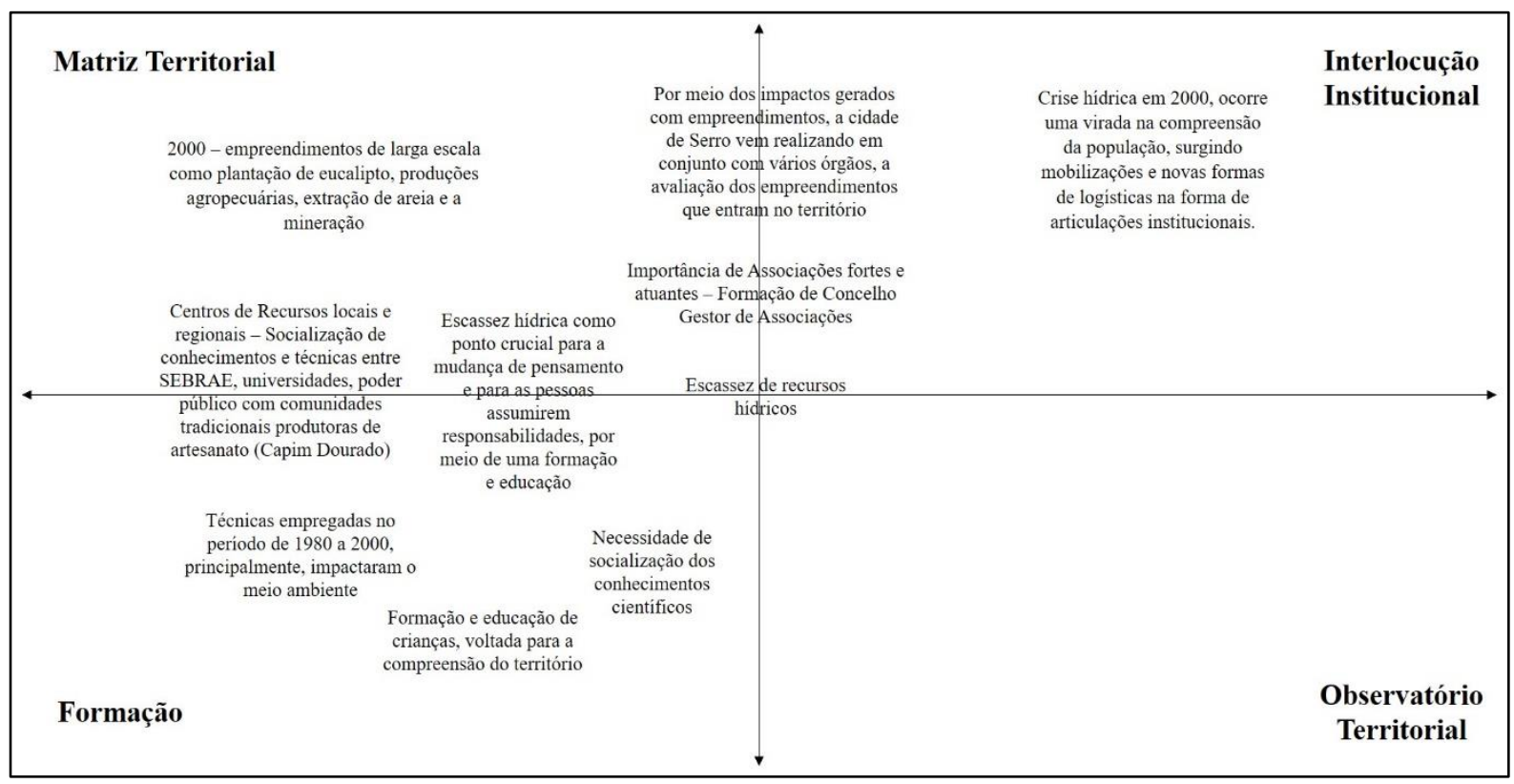

Figura 6 - Compreensões dos atores do território sobre as problemáticas locais

Fonte: Elaborado pelos autores

Por meio de suas visões, estas iniciativas poderiam ser pensadas para a gestão de águas da microrregião, pois elas mostram a importância das parcerias entre os diversos atores nos territórios para a socialização de conhecimentos e a construção de tecnologias apropriadas. Validando essa visão, os atores ressaltam o caso do Capim Dourado, onde as parcerias entre os grupos tradicionais da região com SEBRAE e universidades com objetivo de socialização de conhecimentos entre estes atores, levaram a um novo formato de manejo, onde os impactos sobre os espaços naturais foram minimizados e novos formatos que harmonizam produção e espaços naturais foram estruturados junto com a comunidade, garantindo adequação de seus produtos. 


\subsection{Possibilidades na perspectiva dos atores da microrregião}

O diagnóstico realizado na microrregião de Presidente Kubistchek, sobre as perspectivas dos atores locais, mostraram que a formação da região, derivada da diversidade cultural existente na época, levaram as comunidades aos percursos escolhidos e a crise hídrica nos territórios (Santos \& Marques, 2002; Portugal \& Marques, 2007; Scheunemann \& Oosterbeek, 2012; Dallabrida, 2016; Oosterbeek, Werlen \& Caron, 2017). Por meio do diagnóstico e dos resultados (figuras 4 e 6), os atores tiveram chance de refletir, por meio desta contextualização da formação da comunidade, sobre os conflitos que foram surgindo nos territórios devido à complexidade com que as comunidades foram tomando ao longo do tempo e como estas relações formaram as dinâmicas locais (Dallabrida, 2016; Shiki \& Shiki, 2004). Neste sentido, estas relações dos atores ao longo do tempo em seus espaços de referências, levaram às práticas que ocorreram no território, aos sinônimos de pertencimento que foram sendo configurados/reconfigurados, as relações de poder que foram sendo construídas por meio das trocas, das informações e da comunicação, onde os detentores destes meios definiram os percursos sobre os demais grupos, o território e seus recursos naturais, evidenciando a forma como se estruturam as redes e nós no espaço geográfico (Raffestin \& Santana, 2013).

E por estarem imersos nesse debate e reflexão (figura 7), os atores colocaram a necessidade de repensar o dilema em que se encontravam em relação ao meio ambiente, continuar com o percurso em que se encontravam ou trilhar novos caminhos possíveis (Santos \& Marques, 2002; Portugal \& Marques, 2007; Scheunemann \& Oosterbeek, 2012; Dallabrida, 2016; Oosterbeek, Werlen \& Caron, 2017). 

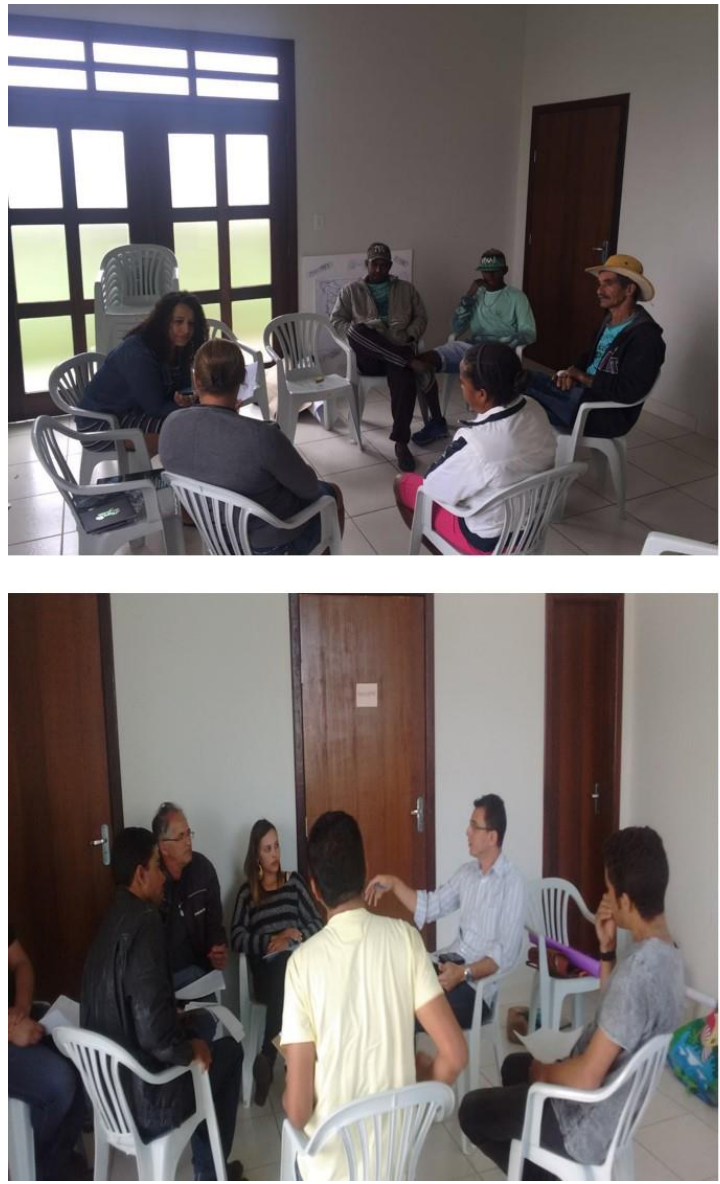
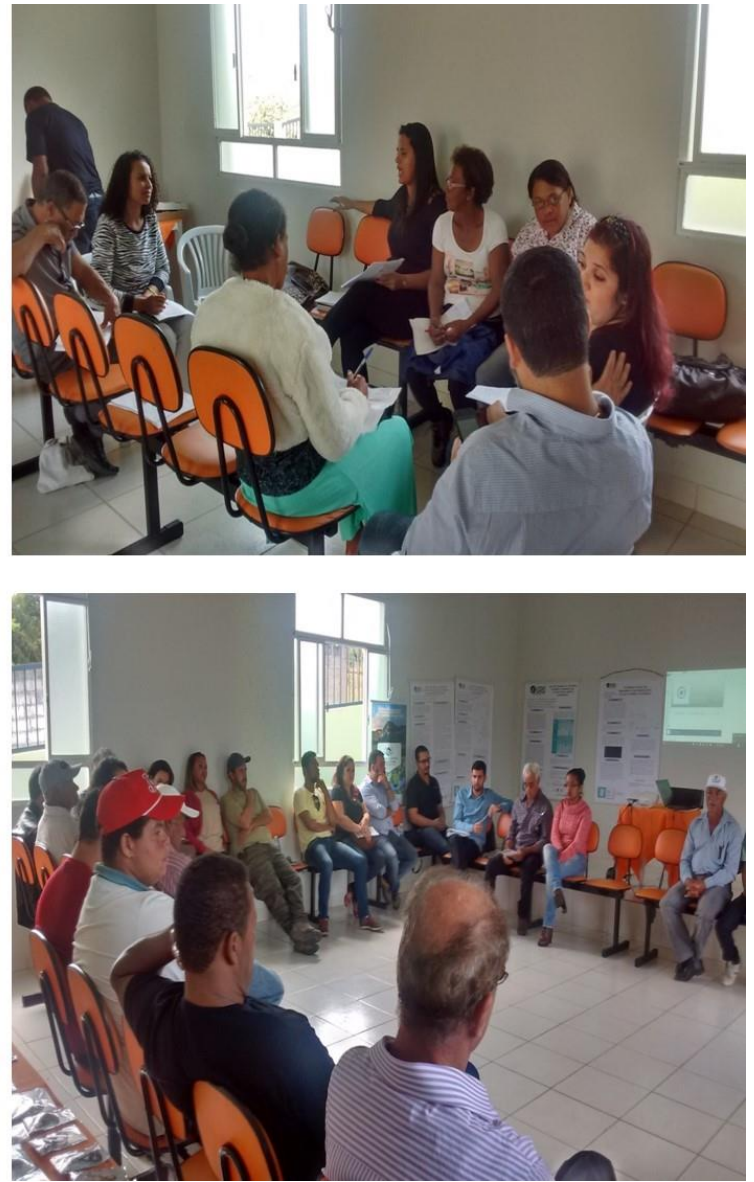

Figura 7 - Segunda rodada de observações participantes e plenária de encaminhamentos Fonte: Elaborado pelos autores

Por meio destes novos cenários, os principais encaminhamentos logísticos e prospectivos, na visão dos atores, deveriam ser como mostra a Figura 8.

Diante desse cenário, foi proposto pelos atores a necessidade de construção de um plano de desenvolvimento que contribuísse para se avançar neste dilema, iniciando as ações por meio das expressões culturais da microrregião (cor mais clara na Figura 8).

Neste sentido, a construção da agenda deveria caminhar para uma didática do dilema existente na microrregião, mas de forma transdisciplinar, socializando conhecimentos e contribuindo para uma interlocução institucional na microrregião (Oosterbeek, 2012; Oosterbeek, Scheunemann \& Santos, 2013; Shiki \& Shiki, 2004; Oosterbeek, Werlen \& Caron, 2017). 


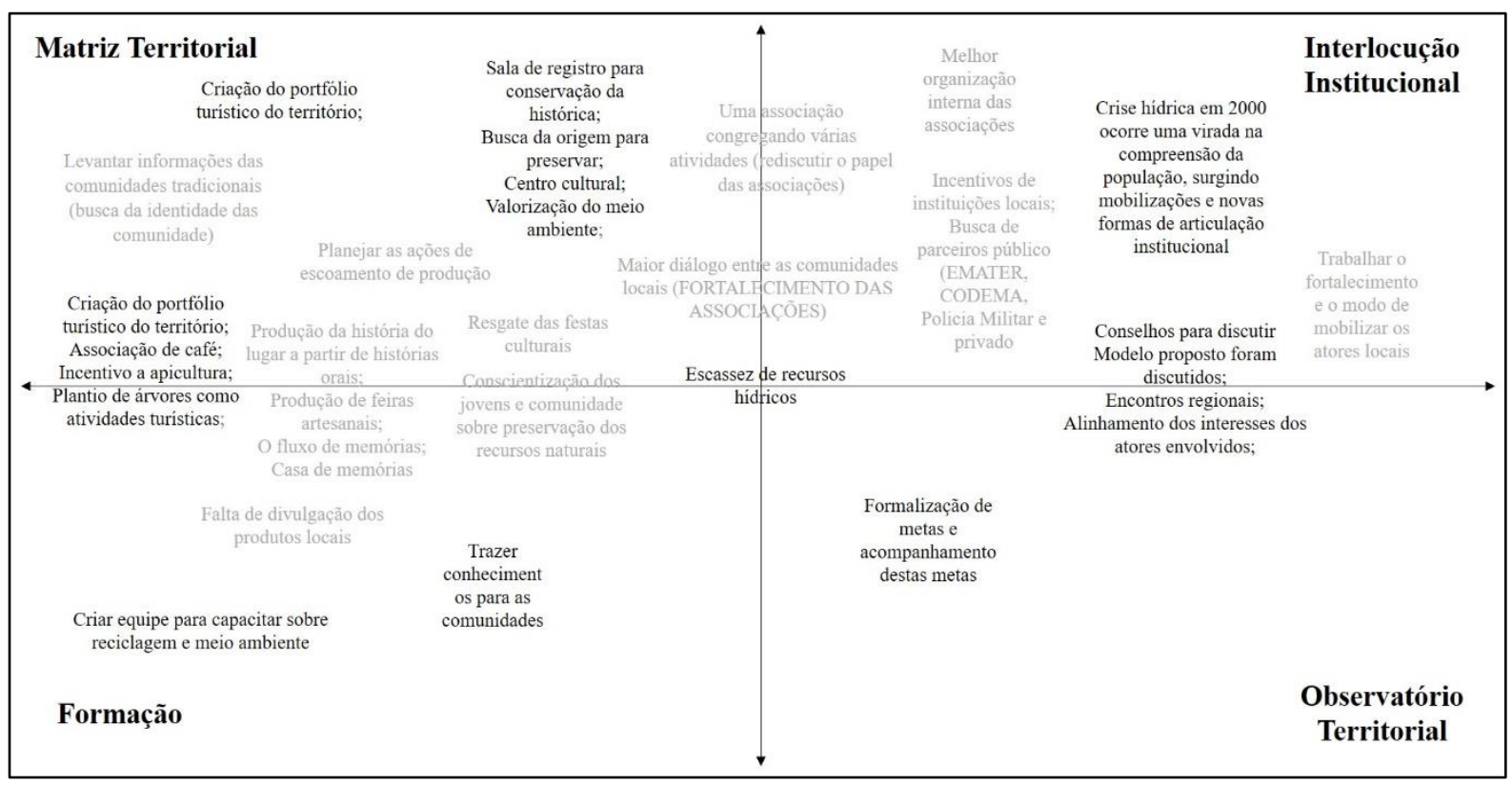

Figura 8 - Novas compreensões locais sobre a Gestão Hídrica

Fonte: Elaborado pelos autores

\subsection{A construção da agenda comum de desenvolvimento}

Para materializar os encaminhamentos produzidos pelos atores da microrregião de Presidente Kubistchek e construir, a partir das novas compreensões sobre o território, uma proposta de Agenda Comum que refletisse esta nova ótica, os técnicos da UFLA nortearam a construção dessa agenda fazendo uso dos quatro eixos de Gestão Cultural Integrada de Território. As diretrizes trabalhadas a partir dos eixos de GCIT foram: Potencialidades do nosso território; Oportunidades estratégicas produtivas; As Necessidades de gestão ambiental e sustentabilidade e; Nossas ações de governança do território. Estas diretrizes se desdobraram em 13 temáticas e para compreendê-las foram definidos os seguintes aspectos: Nossos saberes, conhecimentos e formação; Nossas memórias, documentos e registros; Nossos diálogos, debates e redes; Outras potencialidades nossas; Nossas atividades turísticas, produtivas e industriais; Nossas atividades educacionais e culturais; Nossas ações organizacionais, de planejamentos e projetos; Outras oportunidades estratégicas nossas; Como estamos com relação à conservação ambiental do nosso território; Outras necessidades ambientais e de sustentabilidade; Sobre nosso modelo institucional; Sobre nosso formato organizacional. Este roteiro ainda teve o acréscimo de um debate sobre os 17 Objetivos do Desenvolvimento Sustentável, de forma a englobar 
este debate aos temas tratados pelos atores e como a agenda poderia avançar nos objetivos e nas propostas da Reserva da Biosfera.

O quadro "Novas compreensões locais sobre a Gestão Hídrica" resulta da materialização do roteiro propostos pela equipe UFLA, onde os atores consensuaram a necessidade de trabalhar alguns dados principais (temas em cor mais clara da figura 8) sobre a logica dos aspectos do roteiro e que seriam base para se avançar nos demais aspectos da agenda. Neste sentido, os atores definiram como ponto de partida, trabalhar a diretriz "Potencialidades do nosso território", que se desdobram nos aspectos: Nossos saberes, conhecimentos e formação; Nossas memórias, documentos e registros; Nossos diálogos, debates e redes e; Outras potencialidades nossas. Por meio dos trabalhos destas temáticas, os atores colocaram que o resgate histórico da região, como forma de valorização da identidade territorial, seria fundamental para os próximos passos da agenda.

Diante da construção do diagnóstico realizado na microrregião e posteriormente da agenda, traçados os aspectos iniciais a serem trabalhados e as responsabilidades divididas, as ações posteriores tiveram algumas constatações por meio da percepção dos atores no território e de suas inter-relações:

- Primeiro que as ações traçadas tiveram alguns papeis a serem desempenhados, como o levantamento histórico/culturais por meio de registros, com vista a se construir um Espaço de Memórias e a construção de um portfólio turístico/cultural, porém, os atores responsáveis não conseguiram avançar nas proposições. O que se observa do processo é que os atores esperavam respostas rápidas para situações pontuais, ou seja, visões imediatistas não proporcionaram aos atores vislumbrar possibilidades de médio e longo prazo (Oosterbeek, Werlen \& Caron, 2017). Ainda dentro deste ponto, os saberes locais por si só não proporcionaram uma visão da complexidade social dos territórios aos atores, necessitando de uma compreensão transdisciplinar dos territórios para uma nova abordagem conceitual (Oosterbeek, Werlen \& Caron, 2017).

- A segunda constatação, por meio da percepção de alguns atores, foi que devido ao ano eleitoral, o início dos trabalhos ficou comprometido devido a uma dependência dos poderes executivos municipais. Para os atores, as pessoas devem se empoderar 
do plano para que este não fique na dependência da participação de órgãos ou entidades. Neste sentido, para os atores, existe a necessidade de uma abordagem clara de empoderamento das pessoas sobre os planos e ações a serem traçadas, de forma a não concentrar os encaminhamentos.

- E uma terceira constatação, resultante das duas primeiras constatações, mostra que diante deste cenário, o plano acabou por prover os surgimentos de contradições e conflitos entre os atores, sem espaços de referencias adequados para conciliação das perspectivas dos atores, prejudicando a construção de políticas territoriais e o avanço das potencialidades de médio e longo prazo (Oosterbeek, Werlen \& Caron, 2017).

Diante das constatações, algumas alternativas necessitam ser delineadas para avançar em uma Gestão Cultural Integrada de Território nos territórios.

\section{Contribuições técnicas e metodológicas}

Revisando o método de diagnóstico aplicado, os estudos produzidos, a construção da Agenda de Desenvolvimento da microrregião de Presidente Kubistchek e as constatações do não avanço das ações, algumas considerações foram sugeridas derivadas das experiências dos trabalhos e do debate de GCIT.

A primeira consideração parte do pré-diagnóstico, por meio dos relatos dos atores, os trabalhos com observatórios territoriais poderiam partir de um formato transdisciplinar, onde os dados de caracterização dos territórios fossem confrontados com a percepção das comunidades (Santos \& Marques, 2002; Portugal \& Marques, 2007; Dallabrida, 2016; Oosterbeek, Werlen \& Caron, 2017). Esta proposição seria construída a partir de trabalhos individualizados com os grupos de interesse, e na construção do diagnóstico seria debatido a percepção dos grupos e atores. Esta iniciativa visa empoderar os grupos de interesse e garantir o envolvimento dos atores na construção de possibilidades.

A estratégia do pré-diagnostico, por meio da visão dos atores pode contribuir para que o diagnóstico seja, além de um espaço de reflexão, um momento construção de novos conceitos e compreensões transdisciplinares (Santos, 2000; Hissa, 2011; Oosterbeek, Cura \& Bastos, 2011). 
Como o diagnóstico revela, as comunidades compreendem os percursos escolhidos para o desenvolvimento, porém, elas não visualizam as consequências no longo prazo (Oosterbeek, Werlen \& Caron, 2017). Este fato ocorre, segundo Haesbaert (2004), devido a esses momentos chocarem com as diferentes visões de mundo presentes nos territórios, que refletem também em diferentes territorialidades, e por este fato, os momentos de reflexões sobre a realidade dos territórios e de como as territorialidades configuram e reconfiguram a economia, a sociedade e o meio ambiente, passam a ser fundamentais para proposições de médio e longo prazo. Neste sentido, o empoderamento das pessoas nas fases iniciais de uma proposição de GCIT pode vir a garantir um suporte e subsidio para a comunicação entre os diversos públicos, e como tratado anteriormente, será mais um momento de formação (transdisciplinar) para que as pessoas possam refletir sobre toda a complexidade dos territórios (Santos, 2000; Hissa, 2011; Oosterbeek, Cura \& Bastos, 2011).

A segunda consideração parte do pressuposto que o diagnóstico teve grande relevância para a reflexão dos atores sobre o território, principalmente sobre a importância do Patrimônio Cultural. E como a construção da agenda demonstra, as primeiras ações traçadas foram no sentido de uma valorização dos territórios e as territorialidades dos diversos grupos do espaço geográfico, porém, os momentos específicos de diagnóstico e de construção da agenda não foram o bastante para as pessoas vislumbrarem no longo prazo os benefícios desta construção. Neste sentido, complementarmente a primeira consideração do pré-diagnóstico e do diagnóstico que traz uma reflexão sobre o espaço, tempo e causalidades, como alternativa, o estudo avança quanto à necessidade de uma didática por meio dos Centros de Recursos e Espaços de Memórias (Oosterbeek \& Scheunemann, 2012).

O que se observa com o estudo é o distanciamento entre as gerações e a consequente reconfiguração das territorialidades e formas de apropriação do território. O que demonstra a necessidade de se avançar em espaços para que academia, sociedade civil organizada e principalmente sociedade civil não organizada, possam dialogar e trazer toda a complexidade dos territórios em evidência por meio de um debate de gerações. Para tanto, os Centros de Recursos e Espaços de Memórias (como a museologia) entendidos como locais de socialização de conhecimentos que alinhem momentos de reflexão entre gerações, seriam fundamentais para a compreensão do patrimônio cultural do território, em toda sua 
diversidade de relações homem e paisagem, promovendo múltiplas apropriações simbólicas e materiais e diluindo conflitos entre vários grupos e suas dependências (Bonnemaison, 2002). Por meio desses geossímbolos, a construção de proposições (prospectiva) de médio e longo prazo que estejam alinhadas aos diversos grupos, passa a ser condição indispensável para uma governança local (Bonnemaison, 2002; Scheunemann \& Oosterbeek, 2012).

Este cenário contribui para que os vários atores e grupos compreendam o dilema que perpassam os territórios e como uma abordagem transdisciplinar pode contribuir para construir uma didática do dilema, proporcionando uma nova interlocução institucional e novas dinâmicas territoriais como demonstra a Figura 5 (Santos, 2000; Hissa, 2011; Oosterbeek, Cura \& Bastos, 2011; Scheunemann \& Oosterbeek, 2012).

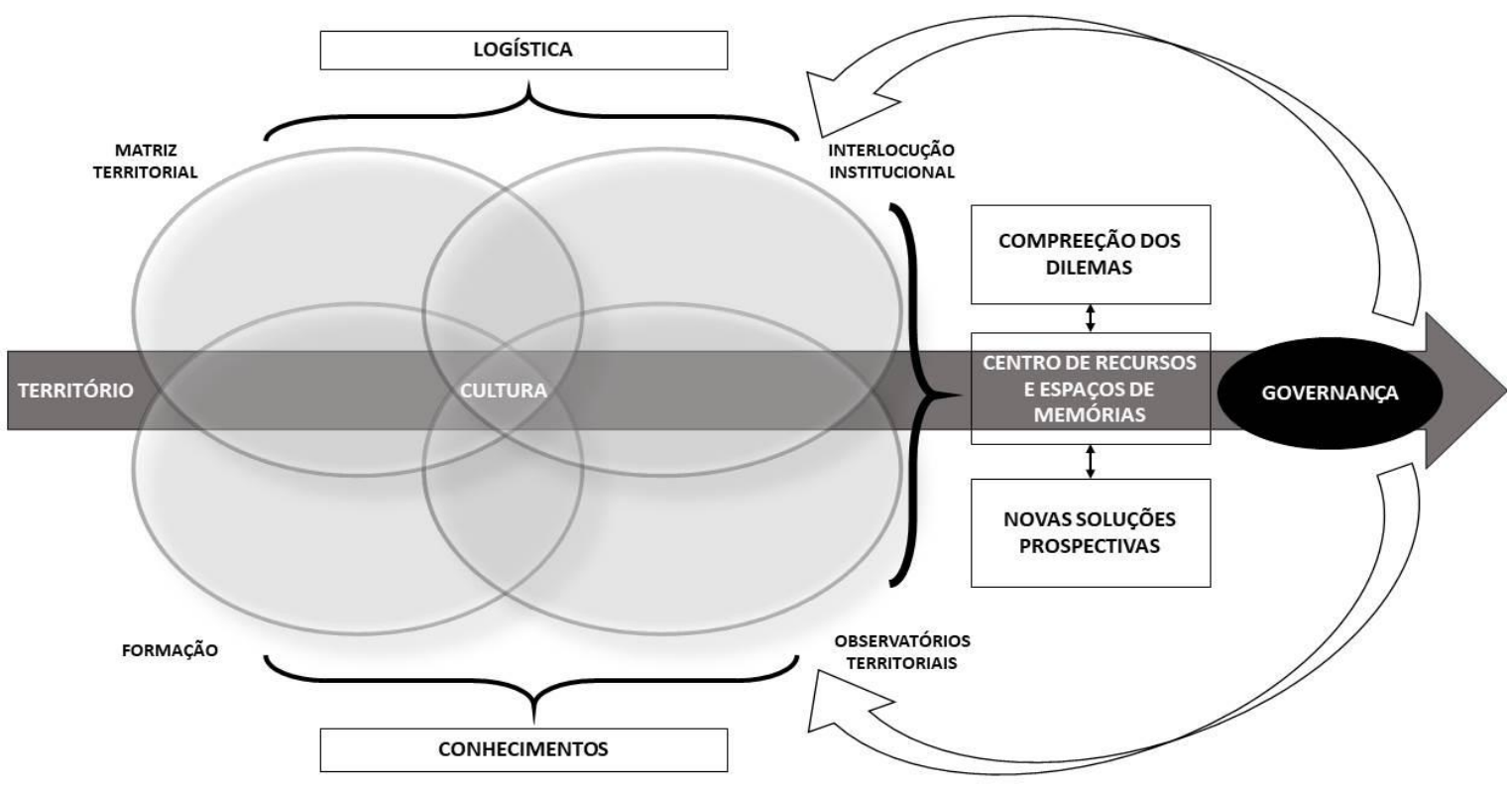

Figura 9 - Novas possibilidades de GCIT na microrregião de Presidente Kubistchek Fonte: Elaborado pelos autores

Por meio das alternativas propostas, novas abordagens transdisciplinares com vista à empoderar cada um dos grupos e atores pode contribuir para novos projetos demonstrativos de GCIT na região da Serra do Espinhaço. 


\section{Conclusão}

O presente trabalho visou refletir sobre a Agenda Comum de Desenvolvimento proposta e colocada em discussão neste estudo, a partir de uma gestão cultural integrada de território na microrregião de Presidente Kubitschek/MG. A discussão realizada se insere na efetivação da nova proposta de desenvolvimento sustentável a partir da Agenda 2030 da ONU. Para isso, o trabalho partiu do projeto Plantando o Futuro, realizado pelo governo de Minas Gerais e o Instituto Espinhaço, com desdobramento na atuação da Universidade Federal de Lavras, onde inicialmente foi realizado um amplo diagnóstico das identidades e especificidades de uma microrregião.

Na sequência, foram demostrados os principais resultados do diagnóstico realizado na microrregião de Presidente Kubitschek/MG, mais precisamente de como vinha ocorrendo a gestão hídrica da região, e a partir dessas reflexões, o que os atores percebem para o curto, médio e longo prazo. Os principais encaminhamentos foram materializados na matriz "Novas compreensões locais sobre a Gestão Hídrica" construída por meio de uma pesquisa acadêmica.

E a partir desta contextualização, o trabalho trouxe um relato de experiência da construção da Agenda Comum da microrregião de Presidente Kubistchek, quais os encaminhamentos construídos derivados das experiências dos atores e como estes encaminhamentos seriam materializados.

Depreende-se do processo que as mesmas constatações, ou limitantes, apontadas pela literatura de GCIT: visão de curto prazo dos atores, derivadas de uma formação utilitarista; abordagens construídas sem um empoderamento dos atores, ou seja, sem uma abordagem transdisciplinar; e uma dependência de entes federados que trabalham as políticas públicas de forma top-down; foram os principais aspectos que levaram a não efetivação dos trabalhos.

Neste sentido, como alternativa e sugestão para novas abordagens metodológicas de GCIT, diante das limitações do estudo, existe a necessidade de um trabalho no pré-diagnóstico e no diagnostico de aproximação dos atores territoriais e outros atores de diferentes níveis escalares, fluxos e redes, mas que estão transitando nos fluxos endógenos e exógenos do espaço geográfico e dos territórios, devido as suas fronteiras permeáveis (Haesbaert, 2004). 
E assim, com estes diversos atores de diferentes níveis escalares, construir um diálogo sobre o dilema que os rodeiam, por meio de um debate de perspectivas diversas. Esta iniciativa visa trazer as percepções dos atores e incorporá-las nas ações ao longo do processo de construção de uma agenda comum para o território. Esse processo objetiva um empoderamento transdisciplinar dos atores, no pré e durante os diagnósticos (Santos, 2000; Hissa, 2011; Oosterbeek, Cura \& Bastos, 2011).

O delinear do estudo mostra que estes momentos, por mais participativos, ainda chocam com as visões de mundo das pessoas. Como alternativa, partindo da visão dos atores sobre os primeiros encaminhamentos da agenda, voltados para uma valorização do Patrimônio Cultural, existe a necessidade de um momento de reflexão sobre o espaço (território), tempo (dinâmicas) e as ações futuras traçadas. Este momento de reflexão parte da estruturação de Centros de Recursos e Espaços de Memórias, entendidos como espaços de formação, mas que alinhem momentos de debates entre gerações de diferentes escalas, valorizando as identidades culturais dos atores e grupos e tratando adequadamente 0 dilema existente nos territórios. Esta proposição busca considerar as opiniões conflituosas derivadas da diversidade e complexidade que os territórios abarcam e por meio desta formação transdisciplinar dos atores, construir proposições de médio e longo prazo que garantam pontes entre visões globais, por meio de entendimentos locais (Santos, 2000; Hissa, 2011; Oosterbeek, Cura \& Bastos, 2011; Scheunemann \& Oosterbeek, 2012).

\section{Agradecimentos}

Primeiramente gostaríamos de agradecer a FAPEMIG e CNPQ pelo financiamento da pesquisa. Os resultados da Tese de Mestrado estão amparados nos dados e análises que foram realizadas sob a orientação do Professor Dr. José de Arimateia Dias Valadão que contribuiu em todas as etapas do estudo e aqui ficam os agradecimentos. Agradecemos a todos os orientandos do Professor Dr. José de Arimateia Dias Valadão que participaram de todo o processo da pesquisa e que geraram outros resultados de grande relevância. Agradecemos ao Instituto Espinhaço por toda a articulação e logística proporcionadas para a realização dos estudos na microrregião de Presidente Kubistchek. Agradecemos a todos os atores da microrregião de Presidente Kubistchek que participaram direta ou indiretamente 
das iniciativas relacionadas à pesquisa desenvolvida pela equipe da Universidade Federal de Lavras. Gostaríamos de agradecer a equipe editorial da Revista Geografia e Ordenamento do Território pelas sugestões e contribuições para a melhoria do artigo.

\section{Referências}

Brasil. Instituto Espinhaço. (Org.). (2017). Instituto Espinhaço. Recuperado de: http://www.institutoespinhaco.org.br/

Bonnemaison, J. (2002). Viagem em torno do território In: CORRÊA, RL, ROSENDAHL, Z.(org.). Geografia Cultural: Um século (3).

Dallabrida, V. R. (2016). Território, governança e desenvolvimento territorial: indicativos teóricometodológicos, tendo a indicação geográfica como referência. São Paulo: LiberArs.

Dallabrida, V. R. (2015). Governança territorial: do debate teórico à avaliação da sua prática. Análise Social, (215), 304-328.

Godecke, M., \& Maurício, G. (2015). Guia para Planos Ambientais Municipais. Pelotas. Ed. Santa Cruz

Hissa, C. E. V. (2011). TRANSDISCIPLINARIDADE: BREVES NOTAS ACERCA DE LIMITES E FRONTEIRAS DA CIÊNCIA MODERNA. Terceiro Incluído, 1(1). doi:10.5216/teri.v1i1.14391

Instituto Espinhaço (Brasil) (Org.). (2018). Plantando o Futuro na Serra do Espinhaço. Recuperado de: http://www.institutoespinhaco.org.br/o-que-fazemos/plantando-o-futuro/.

Haesbaert, R. (2004). Dos múltiplos territórios à multiterritorialidade. Porto Alegre.

Howard, P. (1994). Book Review: Donella H. Meadows, Dennis L. Meadows and Jorgen Randers, Beyond the Limits: Global Collapse or a Sustainable Future (London: Earthscan Publications Limited, 1992, 320 pp., £9.95 pbk.). Millennium: Journal of International Studies, 23(1), 171-173. doi:10.1177/03058298940230010919.

Mónico, L. S., Alferes, V. R., Castro, P. A., \& Parreira, P. M. A. (2017). Observação Participante enquanto metodologia de investigação qualitativa. Anais Congresso íbero-Americano em Investigación Cualitativa, Salamanca, Espanha, 6.

Organização das Nações Unidas. (Org.). (2015). Transformando nosso mundo: a agenda 2030 para o desenvolvimento sustentável. Recuperado de:

https://nacoesunidas.org/wp-content/uploads/2015/10/agenda2030-pt-br.pdf.

Oosterbeek, L. (2013). Direito ambiental ou direito ao ambiente? Uma perspectiva de gestão integrada do território. Aspectos controvertidos do direito ambiental: tutela material e tutela processual. Belo Horizonte: Editora Fórum, 14026-14037.

OosterbeeK, L., Cura, S. \& Bastos, R. L. (2011). Pensar Local... Agir Global. O museu de arte pré-histórica de Mação: memória, intuição e expectativa. Encontro Arqueologia e Autarquias, Cascais, 471-483.

Oosterbeek, L. (2012). Recursos, tecnologia, tradições e gestão integrada do território. Para Desenvolver a Terra: Memórias e Notícias de Geociências No Espaço Lusófono, 17-23. doi:10.14195/978-989-26-0531-9_1

Oosterbeek, L. (2012). Our common future... 25 years later: 10 questions and answers moving from anxiety into the praxis of landscape management. IN: Scheunemann, I, 27-44.

Oosterbeek, L. (2018). Gestão cultural integrada do território: um programa de atuação para as ciências humanas. REDE-Revista Eletrônica do PRODEMA, Fortaleza, 12(03), 53-61.

Oosterbeek, L., Scheunemann, I., \& Santos, L. (2013). Water resources and human behaviour: an integrated landscape management perspective. Cadernos do LEPAARQ (UFPEL), 10(20). Doi: 10.15210/lepaarq.v10i20.2326 
Oosterbeek, L.; Werlen, B.; Caron, L. (2017, eds,). Sociocultural matrices. Transdisciplinary contributions to integrated cultural landscape management. - Vol. 1 ITM, série ARKEOS, vol. 40, 250 p.

Pereira, E. O., Gontijo, B. M., \& Abreu, L. G. Á. de C. (2015). As ecorregiões da reserva da biosfera da serra do espinhaço: elementos para o fortalecimento da conservação da biodiversidade / The ecoregions of biosphere reserve of serra do espinhaço (...) DOI 10.5752/P.2318-2962.2015v25n43p18. Caderno de Geografia, 25(43). doi:10.5752/p.2318-2962.2015v25n43p18

Plantando o Futuro. (2018). Projeto Plantado o Futuro. Recuperado de: http://www.plantandoofuturo.mg.gov.br/index.php/projeto.

Portugal, J. \& Marques, S. (2007). Gestão cultural do território (1a ed.). Porto: Setepés.

Raffestin, C., \& Santana, O. M. G. (2013). Por una geografía del poder. Michoacán: El Colegio de Michoacán.

Sachs, I. (2007). Rumo à ecossocioeconomia: teoria e prática do desenvolvimento. São Paulo: Cortez.

Saquet, M. A. (2011). Por uma geografia das territorialidades e das temporalidades: uma concepção multidimensional voltada para a cooperação e para o desenvolvimento territorial. Outras expressões.

Santos, M. (2002). A natureza do espaço: técnica e tempo, razão e emoção (Vol. 1). Edusp.

Santos, M. (2000). Território e sociedade: entrevista com Milton Santos. São Paulo: Perseu Abramo.

Santos, R. (2008). Espaços de Memória em Mação, construção socialmente participada de perspectivas da Cultura Material. Universidade de Trás-os-Montes e Alto Douro.

Scheunemann, I., \& Oosterbeek, L. (2012). Gestão Integrada do Território: Economia, Sociedade, Ambiente e Cultura. Rio de Janeiro: IBIO.

Shiki, S. F. N. \& Shiki, Shigeo (2004). A Gestão Integrada no Espaço Relativo do Desenvolvimento. Anais XLII Congresso da Sociedade Brasileira de Economia e Sociologia Rural, 2004, Cuiabá.

Unesco (Org.). (2018). Programa Homem e Biosfera. Recuperado de: http://www.unesco.org/new/pt/brasilia/natural-sciences/environment/biodiversity/mab-programme-in-brazil

Veiga, J. E. (2008). Desenvolvimento Sustentável: o desafio do século XXI. (3a ed). Rio de Janeiro: Garamond. 